\title{
Respiratory Chain Defects in the Mitochondria of Cultured Skin Fibroblasts from Three Patients with Lacticacidemia
}

\author{
Brian H. Robinson, * Jewel Ward,‡ Paul Goodyer,\$ and A. Baudet" \\ ${ }^{*}$ Department of Biochemistry and Pediatrics, University of Toronto, and The Research Institute, The Hospital for Sick Children, Toronto, \\ Ontario; ¥Child Development Center, Memphis, Tennessee; §Montreal Children’s Hospital, Montreal, Quebec, Canada; \\ "Department of Pediatrics, Baylor College of Medicine; and Texas Children's Hospital, Houston, Texas
}

\begin{abstract}
The cultured skin fibroblasts from three patients with lacticacidemia were found to have low rates of $1-\left[{ }^{14} \mathrm{C}\right] p y r u v a t e$ oxidation in the face of normal pyruvate.dehydrogenase activity. After incubation with $1 \mathrm{mM}$ glucose, these three cell strains also exhibited lactate/pyruvate ratios which were three times greater than those of controls. In two of the patients, both ATP and oxygen consumption in fibroblast mitochondrial preparations was deficient with NAD-linked substrates but normal with succinate and ascorbate $/ N^{\prime} N^{\prime} N^{\prime} N^{\prime}$ tetramethyl phenylene diamine. In the third patient, ATP synthesis in mitochondrial preparations was deficient with all substrates tested. Measurement of Rotenone-sensitive NADH-cytochrome c reductase in mitochondrial preparations from skin fibroblasts showed that two of the patients had 14 and $18 \%$, respectively, of control activity. In the third patient, cytochrome oxidase activity was $15 \%$ of that in controls. We conclude that respiratory chain defects can be demonstrated in cultured skin fibroblasts with consistency using a number of different techniques.
\end{abstract}

\section{Introduction}

Reported defects in the mitochondrial respiratory chain both in children and in adults have often been associated with chronic lacticacidemia. These defects include deficiencies of NADHCoenzyme $Q$ reductase $(1-7)$, cytochrome b (8-10), succinate cytochrome $c$ reductase $(11,12)$ and cytochrome oxidase $(13-$ 25). Many of these defects are reported as being tissue-specific in that only certain tissues, usually muscle, exhibit the enzyme deficiencies; but except for two sibs with cytochrome oxidase deficiency (24), the deficit in enzyme activity is not demonstrable in fibroblasts. Clinical phenotypes vary from muscular weakness in adults to overwhelming lactic acidosis in infants, with a spectrum of neurological and neuromuscular presenting features in between, and it is not clear why such basic defects should exhibit such heterogeneity.

In the course of screening a population of pediatric patients with chronic lacticacidemia for observable defects in cultured skin fibroblasts, we found a number of cell strains that exhibited low rates of $1-\left[{ }^{14} \mathrm{C}\right]$ pyruvate oxidation to ${ }^{14} \mathrm{CO}_{2}$ in the face of normal activity of the pyruvate dehydrogenase complex. In following up the etiology of this malfunction we have shown in a series of well-documented steps that three of these cell strains

Address reprint requests to Dr. Robinson, Research Institute, The Hospital for Sick Children, 555 University Avenue, Toronto, Ontario, Canada M5G 1 X8.

Received for publication 4 November 1985.

J. Clin. Invest.

(c) The American Society for Clinical Investigation, Inc.

0021-9738/86/05/1422/06 \$1.00

Volume 77, May 1986, 1422-1427 have defects in the mitochondrial respiratory chain. In one of these patients we have published a preliminary investigation suggesting the respiratory chain as the site of the enzyme defect (7).

\section{Case reports}

Patient 1. K.V. was a small-for-gestational-age infant who, after a term delivery, fed poorly for the first week of life. At $10 \mathrm{~d}$ of age the infant developed an acute acidotic episode with tachypnea. By the 12 th $d$ the serum lactate was $30 \mathrm{mM}$ with a serum pyruvate of $0.22 \mathrm{mM}$. Serum 3-hydroxybutyrate was $1.5 \mathrm{mM}$ and acetoacetate $0.04 \mathrm{mM}$. On day 13 the child expired due to overwhelming acidosis. Two previous sibs had died in the neonatal period after a similar course.

Patient 2. I.W. presented at $15 \mathrm{~d}$ with anorexia, weakness, irritability and hypertonic posturing. An electroencephalogram showed focal seizure discharge indicative of diffuse encephalopathy. In the next two days he deteriorated with periods of apnea and then total respiratory failure for which he was intubated. He was found to have lacticacidemia with a blood lactate of $7.3 \mathrm{mM}$ and a blood pyruvate of $0.12 \mathrm{mM}$. The patient expired at $1 \mathrm{mo}$ of age, and at post-mortem the central nervous system was seen to be rarefied with diffuse necrosis of the subcortical white matter and dysmyelination. The parents were first cousins.

Patient 3. W.F. was healthy at birth except for the presence of hypospadias and a micropenis. He had only one testicle, which was undescended. The frontal bones of the forehead were underdeveloped, giving a narrow forehead. At 8 mo the patient was readmitted to hospital with hypoglycemia and acidosis after a urinary tract infection. He was also not thriving and had increased blood lactic acid. Blood lactic acid continued to be elevated at levels between 3.0 and $6.9 \mathrm{mM}$. By $18 \mathrm{mo}$ he could sit up supported, but his development, both physical and mental, was delayed.

\section{Methods}

Chemicals. All chemicals used were analytical grade. Cytochrome e and TMPD were obtained from the Sigma Chemical Co. (St. Louis, Missouri).

Skin fibroblast cultures. Human skin fibroblasts were grown from explants of forearm skin biopsies taken with informed parental consent and cultured in $\alpha$-minimal essential medium supplemented with $10 \%$ fetal calf serum. It is a characteristic of the respiratory chain-deficient cell strains that cell death occurs very rapidly after the glucose in the culture medium has been used up. We therefore had to refeed the cultures at 5-d intervals to keep them growing. In the later investigations, when large numbers of cells had to be grown for isolation of mitochondria, the $\alpha$-medium was supplemented with an additional $5 \mathrm{mM}$ glucose to give a final concentration of $10.5 \mathrm{mM}$ glucose in the culture medium.

Determination of lactate/pyruvate ratios. Confluent skin fibroblast cultures ( $1 \mathrm{mg}$ cell protein) were drained of culture fluid and the medium replaced with a Krebs phosphate buffer $(2 \mathrm{ml})$. The fibroblast cultures were then incubated for $1 \mathrm{~h}$ at $37^{\circ} \mathrm{C}$ to deplete substrate and glycogen reserves. At this point the buffer was replaced by $2 \mathrm{ml}$ of $\mathrm{Krebs}$ phosphate buffer containing $1 \mathrm{mM}$ glucose. After $1 \mathrm{~h}, 0.1 \mathrm{ml} 1.6 \mathrm{M}$ perchloric acid 
was added. The cells were scraped from the dish with the acidified buffer, centrifuged, and separated into supernatant and pellet. The supernatant was assayed for lactate and pyruvate $(26,27)$ and the pellet for protein content.

Determination of enzyme activity. Pyruvate dehydrogenase was measured by the method of Hyland and Leonard (28) and whole cell 1- $\left[{ }^{14} \mathrm{C}\right]$ pyruvate oxidation by the method of Robinson, Taylor, and Sherwood (29). Rotenone-sensitive NADH-cytochrome c reductase was measured in sonicated mitochondrial preparations as described by Moreadith et al. (6), except that sodium azide ( $5 \mathrm{mM}$ ) rather than cyanide was used to inhibit reoxidation of cytochrome $\mathrm{c}$ by cytochrome oxidase. Cytochrome oxidase was determined in mitochondria by the methods described by DiMauro et al. (19). Succinate cytochrome c reductase was measured by following the reduction of cytochrome c at $550 \mathrm{~nm}$ (30).

Measurement of ATP synthesis in fibroblast mitochondria and digitonin-treated fibroblasts. The ability of fibroblast mitochondria to synthesize ATP was tested in two systems, one using isolated mitochondria prepared by the method of Millis and Pious (31) and the other using digitonin-treated fibroblasts (7). In the latter procedure, confluent skin fibroblast cultures in 9-cm Petri dishes were drained of culture medium and the medium replaced by $1 \mathrm{ml}$ of a solution containing $0.25 \mathrm{M}$ sucrose,

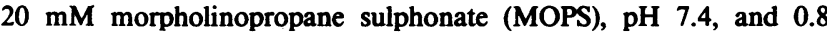
$\mathrm{mg} / \mathrm{ml}$ digitonin. $3 \mathrm{~min}$ later this was removed and replaced with $1 \mathrm{ml}$ of a buffer containing $0.25 \mathrm{M}$ sucrose, $20 \mathrm{mM}$ EDTA, and $20 \mathrm{mM}$ MOPS, $\mathrm{pH}$ 7.4. After $5 \mathrm{~min}$ this medium was replaced with $1 \mathrm{ml}$ of a medium containing $0.25 \mathrm{M}$ sucrose, $25 \mathrm{mM}$ MOPS, pH 7.4, $1 \mathrm{mM}$ EDTA, $5 \mathrm{mM}$ potassium phosphate, $1 \mathrm{mM}$ ADP (no-substrate medium). To assess the potency of various substrates with respect to ATP production, various substrates were added to this basic medium. After $1 \mathrm{~h}$ at $37^{\circ} \mathrm{C}, 0.05 \mathrm{ml} 1.6 \mathrm{M}$ perchloric acid was added, the solution centrifuged to remove protein, and the resulting extract assayed by enzyme fluorimetric methods for ATP content (32). In the case of isolated mitochondria, $30 \mu \mathrm{g}$ mitochondrial protein were added to $200 \mu \mathrm{l}$ of no-substrate medium or substrate containing medium. Incubation was carried out for $1 \mathrm{~h}$ at $37^{\circ} \mathrm{C}$, and $10 \mu 11.6 \mathrm{M}$ perchloric acid added to stop the reaction. Again, after centrifugation to remove precipitated protein, the supernatants were assayed for ATP content.

Measurement of oxygen consumption. We have found that a preparation of cultured skin fibroblasts, treated with low concentrations of digitonin to release cytoplasmic constituents, can be monitored with an oxygen electrode in an analogous fashion to a preparation of isolated mitochondria. To assess the respiration of individual cell strain mitochondria the procedure was carried out as follows: five Petri dishes of confluent fibroblasts (total protein $5 \mathrm{mg}$ ) were drained of culture medium and incubated with $1 \mathrm{ml}$ of a solution containing $0.25 \mathrm{M}$ sucrose, 20

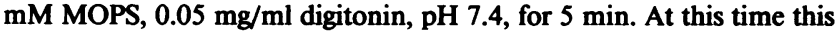
solution was removed and replaced by $1 \mathrm{ml}$ of a solution containing $0.25 \mathrm{M}$ sucrose $20 \mathrm{mM}$ MOPS $1 \mathrm{mM}$ EDTA (SME medium). The permeabilized cells were then scraped off the dishes into the $1-\mathrm{ml}$ aliquots of sucrose medium, centrifuged at 13,000 rpm in an Eppendorf microfuge for $1 \mathrm{~min}$ and the pellets combined and resuspended in $1.5 \mathrm{ml} \mathrm{SME}$ medium. This was added to the chamber of a Clark Oxygen Electrode (Yellow Springs, Texas) and oxygen utilization was measured in response to ADP with a variety of substrates. This technique, though it does not give as high state $3 /$ state 4 ratios as conventionally prepared mitochondria, routinely gives ratios of 3.5 for glutamate plus malate as substrate and 2.2 for succinate as substrate. Since in this type of investigation the rates of oxygen consumption with ADP and phosphate are the most important parameter to measure rather than coupling efficiency, this technique lends itself to study of respiratory chain defects.

\section{Results}

We have reported previously that cell strains from patients with chronic lacticacidemia exist which in spite of having normal

1. Abbreviations used in this paper: $\mathrm{L} / \mathrm{P}$ ratio, lactate to pyruvate ratio; MOPS, morpholinopropane sulphonate; TMPD, $N^{\prime} N^{\prime} N^{\prime} N^{\prime}$ tetramethyl phenylene diamine. activity of the pyruvate dehydrogenase complex have low rates of $1-\left[{ }^{14} \mathrm{C}\right]$ pyruvate oxidation to ${ }^{14} \mathrm{CO}_{2}$ and an abnormal NAD/NADH ratio, determined either by direct measurement (33) or from the lactate/pyruvate ratio in cell cultures (7). Three cell strains were selected for this study which had rates of $1-\left[{ }^{14} \mathrm{C}\right]$ pyruvate which were 38,16 , and $27 \%$ of control rates, respectively (Table $I$ ). The activities of the pyruvate dehydrogenase complex were 88,93 , and $57 \%$, respectively, of that in controls. For purposes of comparison, a pyruvate dehydrogenase-deficient cell strain is included that has $2 \%$ of the normal activity of the pyruvate dehydrogenase complex and $20 \%$ of the normal rate of $1-\left[{ }^{14} \mathrm{C}\right]$ pyruvate oxidation.

Confluent cultures of skin fibroblasts of the patients being studied were incubated for $1 \mathrm{~h}$ in glucose-free phosphate-buffered saline (PBS). Following a further 1-h incubation in PBS with 1 $\mathrm{mM}$ glucose, the accumulation of lactate and pyruvate was measured in the incubation medium. Control cells strains produced lactate at a rate of about $600 \mathrm{nmol} / \mathrm{h}$ per $\mathrm{mg}$ cell protein, and this increases somewhat in the presence of the respiratory inhibitor rotenone. Cell strains from the patients, while giving slightly but not significantly increased rates of lactate production, gave much lower rates of pyruvate production. The resulting lactate/pyruvate ratio in the medium for these patients were some three times greater than in control cell strains. Both the amounts of lactate and pyruvate produced and the ratio of lactate to pyruvate was normal in the pyruvate dehydrogenase deficient cell line. The respiratory inhibitor rotenone reduced the amount of pyruvate produced in a control cell strain and elevated the lactate/pyruvate ratio by a factor of five.

ATP production and oxygen consumption in mitochondria. Mitochondrial ATP production was assessed in two different preparations, firstly in digitonin-treated fibroblast preparations, and secondly in conventionally prepared mitochondrial preparations. In the digitonin-treated fibroblasts ATP production could be stimulated adequately in control cell strains by the addition of either pyruvate plus malate, isocitrate plus malate, succinate plus rotenone, or ascorbate plus $N^{\prime} N^{\prime} N^{\prime} N^{\prime}$ tetramethyl phenylene diamine (TMPD) (Table III). In patients 1 and 2 ATP synthesis was not stimulated by pyruvate or isocitrate plus malate but was adequate for either succinate or ascorbate/ TMPD. In patient 3 ATP synthesis could be stimulated by all substrates, but at reduced rates compared with controls. The isolated mitochondrial preparations, because of their greater pu-

Table I. Enzyme Activities in Control and Respiration-deficient Cell Strains

\begin{tabular}{|c|c|c|c|}
\hline & \multicolumn{2}{|c|}{ Pyruvate dehydrogenase complex } & \multirow{2}{*}{$\begin{array}{l}\text { Whole cell } \\
1-\left[{ }^{14} \mathrm{C}\right] \text { pyruvate } \\
\text { oxidation }\end{array}$} \\
\hline & Native & $\begin{array}{l}\text { Dichloroacetate } \\
\text { activated }\end{array}$ & \\
\hline & nmol/min per mg & nmol/min per mg & nmol/h per mg \\
\hline Controls & $0.451 \pm 0.051(9)$ & $0.600 \pm 0.063(9)$ & $24.3 \pm 4.7(6)$ \\
\hline Patient 11680 & $0.476 \pm 0.066$ & $0.551 \pm 0.155$ & $3.9 \pm 0.9(7)$ \\
\hline Patient 21895 & $0.567 \pm 0.121(5)$ & $0.530 \pm 0.144(5)$ & $9.3 \pm 0.1(11)$ \\
\hline Patient 31909 & $0.251 \pm 0.066(6)$ & $0.343 \pm 0.068(6)$ & $6.8 \pm 1.6(4)$ \\
\hline \multicolumn{4}{|l|}{ PDH deficient } \\
\hline 1373 & $0.015 \pm 0.008(9)$ & $0.012 \pm 0.008(9)$ & $4.9 \pm 1.7(5)$ \\
\hline
\end{tabular}

Determinations were carried out as described in the Methods section. Values are expressed as the mean \pm SEM with the number of determinations shown in parentheses. 
Table II. Production of Lactate and Pyruvate from Glucose by Cultured Skin Fibroblasts in a 1-h Incubation

\begin{tabular}{cccc}
\hline Cell strain no. & Lactate produced & Pyruvate produced & Lactate/pyruvate ratio \\
\hline & nmol/h per mg cell protein & nmol/h per mg cell protein & \\
Control & & & \\
1685 & $620 \pm 58(9)$ & $25.0 \pm 4.7(9)$ & $24.8 \pm 2.7(9)$ \\
1206 & $586 \pm 92(5)$ & $20.7 \pm 4.0(5)$ & $28.3 \pm 3.1(5)$ \\
1228 & $569 \pm 53(3)$ & $33.6 \pm 3.2(3)$ & $16.9 \pm 3.7(3)$ \\
1373 & $710 \pm 58(8)$ & $33.4 \pm 4.7(6)$ & $21.2 \pm 3.8(6)$ \\
PDH Deficient & & & \\
Respiration Deficient & $753 \pm 137(8)$ & $10.5 \pm 1.9(8)$ & $71.7 \pm 5.3(8)$ \\
Patient 1 1680 & $827 \pm 51(5)$ & $6.2 \pm 1.7(5)$ & $133 \pm 23(5)$ \\
$1685+$ Rotenone & $862 \pm 53(5)$ & $9.4 \pm 1.7(5)$ & $93.5 \pm 8.8(5)$ \\
Patient 21895 & $777 \pm 96(4)$ & $6.0 \pm 1.4(4)$ & $137.1 \pm 14.3(4)$
\end{tabular}

Determinations were carried out as described in the Methods section to document the amount of pyruvate and lactate produced by incubating cell cultures $(\sim 1 \mathrm{mg}$ protein) with $1 \mathrm{mM}$ glucose. Values are given as the mean $\pm \mathrm{SEM}$, the number of determinations being given in parentheses.

rity, had a much higher specific activity of ATP production. Patients 1 and 2 again had a greatly compromised ability to synthesize ATP with NAD-linked substrates, while patient 3's ability to synthesize ATP appeared to be about $20 \%$ of normal with all substrates tested.

Oxygen consumption was measured in preparations of mitochondria obtained by mild digitonin treatment of cells. These preparations behaved in an analogous fashion to isolated mitochondrial preparations, but had the advantage that experiments could be performed without having to grow large numbers of cells for mitochondrial preparation. The oxygen consumption of these mitochondria measured polarographically showed that in patients 1 and 2 oxygen consumption was very low with NADlinked substrates, but was normal with succinate or ascorbate/ TMPD (Table IV). In patient 3 , oxygen consumption was slow with NAD-linked substrates, slow with succinate as substrate in state 4 and state 3 , almost up to $50 \%$ normal with succinate in the uncoupled state (plus 2,4 dinitrophenol), and about $20 \%$ of normal with ascorbate/TMPD. 2,4 dinitrophenol addition gave only a poor stimulation of oxygen consumption $(<50 \%)$ with NAD-linked substrates.

Assay of respiratory chain components. In order to obtain reproducible measurements of the respiratory chain components present in cultured skin fibroblast mitochondria, we found that it was necessary first to prepare isolated mitochondria by the protease digestion technique (31). A suspension of purified mitochondria (0.3-0.5 mg protein) in $0.5 \mathrm{ml}$ of a solution containing $2.5 \mathrm{M}$ sucrose, $20 \mathrm{mM}$ tris $\mathrm{HCl}$ (pH 7.4), $1 \mathrm{mM}$ EDTA was made $10 \mathrm{mM}$ with respect to $\mathrm{Mg}^{++}$and then sonicated to disrupt the mitochondria. $25-\mu$ l aliquots of this preparation were used for the assay of NADH cytochrome $c$ reductase (rotenonesensitive), succinate cytochrome $\mathrm{c}$ reductase, and cytochrome oxidase, as described in the Methods section (Table V).

Rotenone-sensitive NADH-cytochrome c reductase was $14 \%$ of controls in mitochondria from patient 1 and $18 \%$ in patient 2 , while patient 3 showed levels not significantly different from

Table III. Production of ATP by Isolated Mitochondria with Different Substrates

\begin{tabular}{|c|c|c|c|c|c|}
\hline Cell strain no. & No substrate & Pyruvate malate & Isocitrate malate & Succinate rotenone & Ascorbate/TMPD \\
\hline & \multicolumn{5}{|c|}{ nmol/h per mg mitochondrial protein } \\
\hline \multicolumn{6}{|c|}{ Conventional } \\
\hline Controls & $34 \pm 10(7)$ & $459 \pm 47(8)$ & $633 \pm 70(8)$ & $960 \pm 71(8)$ & $517 \pm 74(4)$ \\
\hline Patient 11680 & $19 \pm 3$ & $33.7 \pm 2$ & $58.3 \pm 8 \quad(4)$ & $802 \pm 41(4)$ & $304 \pm 54(4)$ \\
\hline Patient 21895 & $19 \pm 2$ & $22 \pm 3$ & $51 \pm 3$ & $670 \pm 54(3)$ & $277 \pm 54(3)$ \\
\hline \multirow[t]{2}{*}{ Patient 31909} & $20 \pm 1$ & $113 \pm 36(4)$ & $118 \pm 36(4)$ & $142 \pm 21(4)$ & $99 \pm 2$ \\
\hline & \multicolumn{5}{|c|}{ nmol/h per mg digitonin fraction protein } \\
\hline \multicolumn{6}{|l|}{ Digitonin } \\
\hline Controls 1685 & $49 \pm 5 \quad(10)$ & $162 \pm 20(6)$ & $201 \pm 23(4)$ & $176 \pm 16(8)$ & $98 \pm 12(4)$ \\
\hline 1228 & $51 \pm 8$ & $142 \pm 29(4)$ & $133 \pm 20(4)$ & $176 \pm 17(3)$ & - \\
\hline 1206 & $44 \pm 10(5)$ & $149 \pm 27(5)$ & $151 \pm 20(4)$ & $200 \pm 21(3)$ & - \\
\hline Patient 11680 & $29 \pm 2 \quad(6)$ & $34 \pm 4 \quad(8)$ & $30 \pm 3 \quad(6)$ & $154 \pm 21(7)$ & $86 \pm 6$ \\
\hline Patient 21895 & $45 \pm 7$ & $42 \pm 1$ & $52 \pm 7$ & $142 \pm 10(4)$ & $69 \pm 10(3)$ \\
\hline Patient 31909 & $28 \pm 2$ & $78 \pm 5 \quad(4)$ & $66 \pm 14(4)$ & $76 \pm 10(4)$ & $49 \pm 2$ \\
\hline
\end{tabular}

Mitochondrial fractions prepared by either conventional or digitonin fractionation techniques were incubated as described in the Methods section with a buffer containing either no substrate, $5 \mathrm{mM}$ pyruvate and $1 \mathrm{mM}$ isocitrate and $0.1 \mathrm{mM}$ malate, $5 \mathrm{mM}$ succinate and $1 \mu \mathrm{M}$ rotenone, or 2 $\mathrm{mM}$ ascorbate and $0.1 \mathrm{mM}$ TMPD. After $1 \mathrm{~h}$, perchloric acid extracts were prepared and ATP content was determined. Values are given for the mean $\pm \mathrm{SEM}$, the number of determinations being given in parentheses. 
Table IV. Oxygen Utilization by Digitonin Mitochondria from Cultured Skin Fibroblasts

\begin{tabular}{|c|c|c|c|c|c|c|}
\hline & \multicolumn{2}{|l|}{ Glutamate/Malate } & \multicolumn{3}{|l|}{ Succinate } & \multirow{2}{*}{$\frac{\text { Ascorbate/TPMD }}{\text { Dinitrophenol }}$} \\
\hline & State 4 & State 3 & State 4 & State 3 & Dinitrophenol & \\
\hline & \multicolumn{5}{|c|}{ ng atoms $0 /$ min per $\mathrm{mg}$ protein } & \\
\hline \multicolumn{7}{|l|}{ Controls } \\
\hline 1268 & $1.18 \pm 0.44(4)$ & $3.45 \pm 0.33(5)$ & $2.96 \pm 0.60(5)$ & $7.01 \pm 0.77(4)$ & $9.3 \pm 0.7$ & - \\
\hline 1206 & $1.06 \pm 0.23(8)$ & $3.67 \pm 0.53(4)$ & $3.52 \pm 0.97(4)$ & $7.4 \pm 1.1$ & $11.7 \pm 1.8$ & $34.2 \pm 7.3(3)$ \\
\hline \multicolumn{7}{|l|}{$\begin{array}{c}\text { Respiration } \\
\text { deficient }\end{array}$} \\
\hline Patient 11680 & $0.07 \pm 0.05(3)$ & $0.39 \pm 0.09(3)$ & $3.62 \pm 0.13(4)$ & $6.13 \pm 0.35(4)$ & $9.99 \pm 0.45(4)$ & $32.3 \pm 6.3(4)$ \\
\hline Patient 21895 & $0.52 \pm 0.07(4)$ & $0.88 \pm 0.19(4)$ & $2.45 \pm 0.65(3)$ & $5.66 \pm 0.45(5)$ & $8.0 \pm 0.67(3)$ & $22.6 \pm 6.9(2)$ \\
\hline Patient 31909 & $0.27 \pm 0.20$ & $0.73 \pm 0.39$ & $0.56 \pm 0.36(2)$ & $1.66 \pm 1.1$ & $5.36 \pm 0.97(5)$ & $5.7 \pm 1.7(5)$ \\
\hline
\end{tabular}

Mitochondria prepared by digitonin fractionation were added to the chamber of a Clark oxygen electrode in a sucrose buffer and the oxygen consumption measured as described in the Methods section. For each substrate, the rate was measured in the absence of added ADP (state 4), in the presence of ADP (state 3), or in the presence of $0.1 \mathrm{mM}$ dinitrophenol. The three substrate categories used were: $5 \mathrm{mM}$ glutamate with $1 \mathrm{mM}$ malate, $5 \mathrm{mM}$ succinate with $1 \mu \mathrm{M}$ rotenone, and $2 \mathrm{mM}$ ascorbate with $0.2 \mathrm{mM}$ TMPD. Values are given as the mean \pm SEM, the number of determinations being given in parentheses.

normal. Succinate cytochrome $\mathrm{c}$ reductase had normal activity in patients 1 and 2, but was $54.3 \%$ of normal in patient 3. Cytochrome oxidase was $181 \%$ of the control values in patient 1 , $108 \%$ in patient 2 , and $15.2 \%$ in patient 3 .

\section{Discussion}

The initial observation that cell strains with low $1-\left[{ }^{14} \mathrm{C}\right]$ pyruvate oxidation rates and normal activities of the pyruvate dehydrogenase complex had an abnormal lactate/pyruvate $(\mathrm{L} / \mathrm{P})$ ratio gave the first indication that a respiratory chain defect might be operative. Cells with a pyruvate dehydrogenase or pyruvate carboxylase defect do not have this type of abnormality. The increased $\mathrm{L} / \mathrm{P}$ ratio is a reflection of the redox state of the cytosolic compartment (34), such that an $\mathrm{L} / \mathrm{P}$ ratio of 25 indicates an NAD/NADH ratio of $360: 1$ and an $L / P$ ratio of 75 indicates an NAD/NADH ratio of 120:1. This more reduced cytosolic redox state could have in these cases been due to a defect in the system that transports reducing equivalents into the mitochondria (35) or to a defect in the oxidation of intramitochondrial NADH. In this latter case there would have been a decreased intramitochondrial NAD/NADH ratio that by equilibrium would be reflected in a more reduced cytosolic redox state.

Table V. Activity of the Components of the Respiratory Chain in Cultured Skin Fibroblast Mitochondria

\begin{tabular}{|c|c|c|c|}
\hline Cell line & $\begin{array}{l}\text { Succinate } \\
\text { cytochrome c } \\
\text { reductase }\end{array}$ & $\begin{array}{l}\text { NADH- } \\
\text { cytochrome c } \\
\text { reductase } \\
\text { (士rotenone) }\end{array}$ & $\begin{array}{l}\text { Cytochrome } \\
\text { oxidase }\end{array}$ \\
\hline \multicolumn{4}{|c|}{ nmol/min per mg mitochondrial protein } \\
\hline Controls & $88.0 \pm 7.1$ & $54.2 \pm 5.1(10)$ & $39.9 \pm 6.3(8)$ \\
\hline 1680 Patient 1 & $104.1 \pm 12.8(4)$ & $7.6 \pm 1.6(4)$ & $72.5 \pm 8.5(4)$ \\
\hline 1895 Patient 2 & $113.0 \pm 14.1(4)$ & $10.0 \pm 2.3(5)$ & $42.9 \pm 4.1(4)$ \\
\hline 1909 Patient 3 & $47.8 \pm 6.8$ & $42.9 \pm 4.1(4)$ & $7.7 \pm 1.2(9)$ \\
\hline
\end{tabular}

Determinations were carried out as described in the Methods section using mitochondria prepared by the protease digestion technique (31) which had been sonicated in the presence of $10 \mathrm{mM} \mathrm{Mg} \mathrm{Mg}^{++}$in a medium containing $0.25 \mathrm{M}$ sucrose, $20 \mathrm{mM}$ tris $\mathrm{HCl}$ (pH 7.4). Values are given as the mean $\pm \mathrm{SEM}$, the number of determinations being given in parentheses.
The decreased ability of mitochondrial preparations to synthesize ATP with specific substrates can be used not only to document the presence of a defect in the respiratory chain but also to locate the site of the defect. Thus, in patients 1 and 2, the inability to make ATP from NAD-linked substrates while having normal ATP synthesis with succinate and ascorbate TMPD places the defect between NADH and CoQ in the respiratory chain. In patient 3 the decreased ATP synthesis with all respiratory substrates would indicate a number of possible problems to include $(a)$ a defect in the translocation of ADP and ATP into the mitochondria, $(b)$ a defect in the oligomycinsensitive ATPase, $(c)$ a defect in the coupling of electron transport to oxidative phosphorylation, and $(d)$ a defect in cytochrome oxidase.

The measurement of polarographic oxygen consumption in mitochondrial preparations from these patients was also instrumental in documenting the site of the lesions. Patients 1 and 2 again showed poor rates of oxygen consumption for NAD-linked substrates with normal rates for succinate and ascorbate/TMPD. The block in respiration could not be released by the addition of dinitrophenol, indicating a block in electron transport between NADH and CoQ. With patient 3, oxygen consumption, like ATP synthesis, was markedly decreased with all substrates. Dinitrophenol gave a good stimulation of succinate-driven oxygen consumption, but not with NAD-linked substrates. This at first led us to investigate a possible defect in ADP translocation or coupling, but experiments measuring dinitrophenol-stimulated ATPase activity in whole mitochondria gave only normal values for patient 3 (results not shown). Measurement of the respiratory chain components, however, demonstrated unequivocally that the defect in patient 3 resided in the cytochrome oxidase complex and that the defects in patient 1 and 2 resided in the NADH$\mathrm{CoQ}$ reductase enzyme complex. The explanation for the rather misleading stimulation of succinate oxidation with dinitrophenol probably lies in the availability of reducing equivalents to drive the cytochrome oxidase reaction, the flow of electrons from succinate dehydrogenase being faster in the presence of an uncoupling agent.

An examination of the cases of muscle NADH-CoQ reductase deficiency in the literature reveals six cases, all but one having a late onset and muscle weakness in childhood (1-5). The case 
described by Moreadith et al. (6) is of an infant who died at a few months of age with severe lacticacidemia. The cases we present here are very similar to this latter case in terms of their clinical progress and severity of lactic acidosis. The locality of the defect in the above-mentioned case (6) was centered in one of the iron sulphur proteins in the NADH-CoQ reductase complex by measurement of abnormal electron paramagnetic resonance spectroscopy in submitochondrial particles. The amount of material required precludes this type of measurement in fibroblast mitochondria at this time. Since there are at least 25 different polypeptide components in the NADH-CoQ reductase complex (36), it is quite possible that heterogeneity exists among the different patients with an overall defect in this complex. We suggested that some of these polypeptides might be encoded by the mitochondrial genome (7) a fact that has since been elegantly shown for six of them by Chomyn et al. (37). Since there is no evidence of maternal inheritance of the defect in either of our patients, it is unlikely that the defect we describe resides in a mitochondrially encoded protein.

The clinical presentation of patients with muscle cytochrome oxidase deficiency is again heterogenous. Many of the patients have lacticacidemia, but the age of onset of problems divides the patients into two groups, with presentation either in childhood or in infancy. One group with onset in infancy has Fanconi syndrome $(15-18,20)$. Others with an early onset have a combination of growth retardation and neurological problems (13, $14,19,22)$. The initial presenting features of our patient 3 of lacticacidemia and micropenis have been added to now by a continuing delayed physical and neurological development. This does not seem to fit exactly with any described cases in the literature, but might have been similar to the group with growth retardation and neurological problems (above). Cytochrome oxidase again is an enzyme complex with 13 subunit polypeptides, three of which are encoded by the mitochondrial genome. Deficiencies in the complex are obviously going to be heterogenous and in the absence of any evidence maternal transmission will be in the nucleus-encoded polypeptides (38). Since the three mitochondrially encoded proteins are the actual catalytic subunits of the complex which carry out the electron transport function (38), it will be interesting to find out exactly how a defect in one of the regulatory proteins can reduce the activity to $20 \%$ of normal.

\section{Acknowledgments}

Dr. Robinson thanks the Medical Research Council of Canada and the National Foundation of the March of Dimes for their support in this work.

\section{References}

1. Morgan-Hughes, J. A., P. Darveniza, D. N. Landon, J. M. Land, and J. B. Clark. 1979. A mitochondrial myopathy with a deficiency of respiratory chain NADH-CoQ reductase activity. J. Neurol. Sci. 43:2746.

2. Busch, H. F. M., H. R. Scholte, W. F. Arts, and I. E. M. LuytHouwen. 1981. A mitochondrial myopathy with a respiratory chain defect and carnitine deficiency. In Mitochondria and muscular diseases. H. F. M. Busch, F. G. I. Jennekens, and H. R. Scholte, editors. Mefar. Beetsterzwaag, Netherlands. 207-211.

3. Prick, M. J. J., F. J. M. Gabreels, W. O. Renier, J. M. F. Trijbels, R. C. A. Sengers, and J. D. Slooff. 1981. Progressive infantile poliodystrophy. Association with disturbed pyruvate oxidation in miscle and liver. Arch. Neurol. 38:767-772.
4. Land, J. M., J. M. Hockaday, J. T. Hughes, and B. D. Ross. 1981. Childhood mitochondrial myopathy with opthalmoplegia. J. Neurol. Sci. 51:371-382.

5. Land, J. M., J. A. Morgan-Hughes, and J. Clark. 1981. Mitochondrial myopathy. Biochemical studies revealing a deficiency of NADH-cytochrome b reductase activity. J. Neurol. Sci. 50:1-13.

6. Moreadith, R. W., M. L. Batshaw, T. Ohnishi, D. Kerr, B. Knox, D. Jackson, R. Hruban, J. Olson, B. Reynafarse, and A. L. Lehninger. 1984. Deficiency of the iron-sulfur clusters of mitochondrial reduced nicotinamide-adenine dinucleotide-ubiquinone oxidoreductase (Complex I) in an infant with congenital lactic acidosis. J. Clin. Invest. 74:685697.

7. Robinson, B. H., N. McKay, P. Goodyer, and G. Lancaster. 1985. Defective intramitochondrial NADH oxidation in skin fibroblasts from an infant with fatal neonatal lacticacidemia. Am. J. Hum. Genet. 37: 938-946.

8. Morgan-Hughes, J. A., P. Darveniza, and S. N. Kajn. 1977. A mitochondrial myopathy characterised by a deficiency in reducible cytochrome b. Brain. 100:617-640.

9. Morgan-Hughes, J. A., D. J. Hayes, J. B. Clark, D. N. Landon, M. Swash, R. J. Stark, and P. Rudge. 1982. Mitochondrial encephalomyopathies. Biochemical studies in two cases revealing defects in the respiratory chain. Brain. 105:553-582.

10. Spiro, A. J., C. L. Moore, J. W. Prieas, P. M. Strasberg, and J. Rapin. 1970. A cytochrome related inherited disorder of the nervous system and muscle. Arch. Neurol. 23:103-112.

11. Sengers, R. C. A., J. C. Fischer, J. M. F. Trijbels, W. Ruitenbeek, A. M. Stadhouders, H. J. Ter Laak, and H. H. J. Jaspar. 1983. A mitochondrial myopathy with a defective respiratory chain and carnitine deficiency. Eur. J. Pediatr. 140:332-337.

12. Darley-Usmar, V. M., N. G. Kennaway, N. R. M. Buist, and R. A. Capaldi. Deficiency in ubiquinone cytochrome $\mathrm{c}$ reductase in a patient with mitochondrial myopathy and lactic acidosis. 1983. Proc. Natl. Acad. Sci. USA. 80:5103-5106.

13. Monnens, L., F. Gabreels, and J. Willems. 1975. A metabolic myopathy associated with chronic lacticacidemia, growth failure and nerve deafness. J. Pediatr. 86:983.

14. Willems, J. L., L. A. H. Monnens, J. M. F. Trijbels, J. H. Veerkamp, A. E. F. H. Meyer, K. Van Dam, and U. Van Haelst. 1977. Leigh's encephalomyelopathy in a patient with cytochrome c oxidase deficiency in muscle tissue. Pediatrics. 60:850-857.

15. Van Biervliet, J. P. G. M., L. Bruinvis, D. Ketting, P. K. De Bree, C. Ven der Heiden, S. K. Wadman, J. L. Willems, H. Bookelman, U. Van Haelst, and L. A. H. Monnens. 1977. Hereditary mitochondrial myopathy with lacticacidemia, a DeToni-Fanconi-DeBre syndrome and a defective respiratory chain in voluntary striated muscles. Pediatr. Res. 11:1088-1092.

16. DiMauro, S., J. R. Mendell, Z. Sahenk, D. Bachman, A. Scarpa, R. M. Scofield, and C. Reiner. 1980. Fatal infantile mitochondrial myopathy and renal dysfunction due to cytochrome-c-oxidase deficiency. Neurology. 30;795-804.

17. Heiman-Patterson, T. D., E. Bonilla, S. DiMauro, J. Foreman, and D. L. Schotland. 1982. Cytochrome-c-oxidase deficiency in a floppy infant. Neurology. 32:898-900.

18. Stansbie, D., R. L. Dormer, I. A. Hughes, P. E. Minchom, G. A. F. Hendry, O. T. G. Jones, A. R. Cross, H. S. A. Sherratt, D. M. Turnbull, and M. A. Johnson. 1982. Mitochondrial myopathy with skeletal muscle cytochrome oxidase deficiency. J. Inherit. Metab. Dis. (Suppl 1). 5:2728.

19. DiMauro, S., J. F. Nicholson, A. P. Hays, A. B. Eastwood, A. Papadimitriou, R. Koeningsberger, and D. C. DeVivo. 1983. Benign infantile mitochondrial myopathy due to reversible cytochrome $\mathrm{c}$ oxidase deficiency. Ann. Neurol. 14:226-234.

20. Muller-Hocker, J., D. Pongratz, Th. Deufel, F. M. F. Trijbels, W. Endres, and G. Hubner. 1983. Fatal lipid storage myopathy with deficiency of cytochrome-c-oxidase and carnitine. A contribution to the combined cytochemical-finestructural identification of cytochrome-coxidase in longterm frozen muscle. Virchows Arch. Pathol. Anat. Physiol. Klin. Med. 399:11-23. 
21. Prick, M. J. J., F. J. M. Gabreels, J. M. F. Trijbels, A. J. M. Janssen, R. Le Coultre, K. Van Dam, H. H. J. Jaspar, E. J. Ebels, and A. A. W. Op de Coul. 1983. Progressive poliodystrophy (Alpers' disease) with a defect in cytochrome $\mathrm{aa}_{3}$ in muscle: a report of two unrelated patients. Clin. Neurol. Neurosurg. 85:57-70.

22. Sengers, R. C. A., J. M. F. Trijbels, J. A. J. M. Bakkeren, W. Ruitenbeek, J. C. Fischer, A. J. M. Janssen, A. M. Stadhouders, and H. J. Ter Laak. 1983. Deficiency of cytochrome $b$ and $a_{3}$ in muscle from a floppy infant with cytochrome oxidase deficiency. Eur. J. Pediatr. 141:178-180.

23. Trijbels, F., R. Sengers, L. Monnens, A. Janssen, J. Willem, H. Ter Laak, and A. Stadhouders. 1983. A patient with lactic acidaemia and cytochrome oxidase deficiency. J. Inherit. Metab. Dis. (Suppl 2). 6: 127-128.

24. Miyabayashi, S., K. Narisawa, K. Tada, K. Sakai, K. Kobayashi, and Y. Kobayashi. 1983. 2 Siblings with Cytochrome-C-Oxidase Deficiency. J. Inher. Metab. Dis. 6:121.

25. Bresolin, N., M. Zeviani, E. Bonilla, R. H. Miller, R. W. Leech, S. Shanski, M. Nakagawa, and S. DiMauro. 1985. Fatal infantile cytochrome $\mathrm{c}$ oxidase deficiency. Decrease of immunologically detectable enzyme in muscle. Neurology. 35:802-812.

26. Weiland, O. 1965. $\mathrm{L}+$ ) Lactate determination with lactate dehydrogenase from yeast. In Methods of Enzymatic Analysis. H. U. Bergemeyer, editor. Academic Press, New York. p. 271.

27. Bergemeyer, H. U., and E. Brent. 1965. Pyruvate. In Methods in Enzymatic Analysis. H. U. Bergemeyer, editor. Academic Press, New York: p. 271.

28. Hyland, K., and J. V. Leonard. 1983. Revised assays for the investigation of congenital lactic acidosis using ${ }^{14} \mathrm{C}$-ketoacids eliminating problems associated with spontaneous decarboxylation. Clin. Chim. Acta. 133:177-187.

29. Robinson, B. H., J. Taylor, and W. G. Sherwood. 1980. The genetic heterogeneity of lactic acidosis: occurrence of recognisable inborn errors of metabolism in a pediatric population with lacticacidosis. Pediatr. Res. 14:956-962.

30. Fischer, J. C., W. Ruitenbeek, A. M. Stadhouders, J. M. F. Trijbels, R. C. A. Sengers, A. J. M. Janssen, and J. H. Veerkämp. 1985. Investigation of mitochondrial metabolism in small human skeletal muscle biopsy specimens. Clin. Chim. Acta. 145:89.

31. Millis, A. J. T., and D. A. Pious. 1973. Oxidative phosphorylation in mitochondria isolated from human fibroblasts. Biochim. Biophys. Acta. 292:73-77.

32. Williamson, J. R., and B. Corkey. 1969. Assays of intermediates of the citric acid cycle and related compounds by fluorimetric enzyme method. Methods Enzymol. 13:435-573.

33. Robinson, B. H., J. Taylor, B. Francois, A. L. Beaudet, and D. F. Peterson. 1983. Lacticacidosis and neurological deterioration in a child with compromised pyruvate oxidation due to an intracellular redox problem. Eur. J. Pediatr. 140:98-101.

34. Krebs, H. A. 1973. Pyridine nucleotides and rate control. Symp. Soc. Exp. Biol. 17:299-318.

35. Robinson, B. H., and M. L. Halperin. 1970. Transport of reduced nicotinamide adenine dinucleotide into mitochondria of rat white adipose tissue. Biochem. J. 116:229-234.

36. Heron, C. S., I. Smith, and C. I. Ragan. 1979. An analysis of the polypeptide composition of bovine heart mitochondrial NADH-ubiquinone oxidoreductase by two dimensional polyacrylamide gel electrophoresis. Biochem. J. 181:435-443.

37. Chomyn, A., P. Mariottini, M. W. J. Leeter, C. I. Ragan, A. Yagi-Matsuno, Y. Hatefi, R. F. Doolittle, and G. Attardi. 1985. Six unidentified reading frames of human mitochondrial DNA encode components of the respiratory-chain NADH-dehydrogenase. Nature (Lond.). 314:592-597.

38. Saraste, M. 1983. How complex is a respiratory complex. Trends Biochem. Sci. 8:139-142. 